\title{
Oxygen compared to air during exercise training in COPD with exercise-induced desaturation
}

\author{
Jennifer A. Alison ${ }^{1,2}$, Zoe J. McKeough¹, Regina W.M. Leung ${ }^{3}$, \\ Anne E. Holland $\mathbb{1}^{4,5,6}$, Kylie Hill ${ }^{7,8}$, Norman R. Morris ${ }^{9,10}$, Sue Jenkins ${ }^{7,8,11}$, \\ Lissa M. Spencer ${ }^{12}$, Catherine J. Hill ${ }^{6,13}$, Annemarie L. Lee '14, Helen Seale ${ }^{15^{\prime}}$, \\ Nola Cecins ${ }^{11}$ and Christine F. McDonald ${ }^{6,16}$
}

@ERSpublications

Exercise training improved exercise capacity and quality of life in normoxaemic COPD patients who demonstrated oxygen desaturation during exercise, with no greater improvement with supplemental oxygen during exercise training compared to air http://ow.ly/7hRP30o3vxu

Cite this article as: Alison JA, McKeough ZJ, Leung RWM, et al. Oxygen compared to air during exercise training in COPD with exercise-induced desaturation. Eur Respir J 2019; 53: 1802429 [https://doi.org/ 10.1183/13993003.02429-2018].

ABSTRACT Almost half the patients referred to pulmonary rehabilitation with chronic obstructive pulmonary disease (COPD) desaturate during exercise. Although oxygen supplementation may ameliorate oxygen desaturation, the effects on outcomes of exercise training have not been rigorously evaluated. This study aimed to determine whether supplemental oxygen during exercise training was more effective than medical air in improving exercise capacity and health-related quality of life (HRQoL) in people with COPD.

People with COPD who demonstrated oxygen desaturation $<90 \%$ during the 6 -min walk test were recruited to this multicentre trial with randomisation (independent, concealed allocation) to either an Oxygen group or Air group, blinding (participants, exercise trainers and European Respiratory Journal assessors) and intention-to-treat analysis. Both groups received the respective gas from concentrators via nasal prongs at $5 \mathrm{~L} \cdot \mathrm{min}^{-1}$ during exercise training consisting of treadmill and cycle exercise, three times per week for 8 weeks. Primary outcomes were the endurance shuttle walk test (ESWT) time and Chronic Respiratory Disease Questionnaire (CRQ)-Total score.

111 participants $(60$ males), mean \pm SD age $69 \pm 7$ years, with moderate to severe COPD were recruited and 97 completed (Oxygen group $n=52$; Air group $n=45$ ). At the end of the 8-week training programme there were no between-group differences in change in ESWT (mean difference $15 \mathrm{~s}$ (95\% CI -106-136 s) or change in CRQ-Total ( 0.0 points ( $95 \%$ CI $-0.3-0.3$ points)). Within-group changes at end-training were significant for ESWT and CRQ-Total (all $\mathrm{p}<0.01$ ).

Exercise capacity and HRQoL improved in both groups, with no greater benefit from training with supplemental oxygen than medical air.

This article has supplementary material available from erj.ersjournals.com

This study is registered at www.anzctr.org.au with identifier number ACTRN 12612000395831.

Received: Dec 212018 | Accepted after revision: March 062019

Copyright OERS 2019 


\section{Introduction}

Pulmonary rehabilitation is an important component of the management of people with chronic obstructive pulmonary disease (COPD), with strong evidence of efficacy [1]. Clinically significant improvements in exercise capacity, breathlessness, fatigue and health-related quality of life (HRQoL) are consistently documented in randomised controlled trials of pulmonary rehabilitation that include an exercise training component [1]. Exercise-induced oxygen desaturation is common among people with COPD, with up to $47 \%$ of patients referred to pulmonary rehabilitation demonstrating a decrease in oxygen saturation measured by pulse oximetry $\left(\mathrm{SpO}_{2}\right)$ to $<90 \%$ during a field walking test $[2,3]$. Patients who desaturate may not tolerate high-intensity exercise [4], and healthcare professionals may strive to minimise exercise-induced desaturation by decreasing training intensity and/or imposing mandatory rests. This reduction in exercise intensity is likely to limit the effectiveness of training [5].

Physiological studies have demonstrated that supplemental oxygen during an acute bout of exercise reduces minute ventilation at equivalent work rates and delays the onset of dynamic hyperinflation and associated dyspnoea [6-9], thus augmenting exercise capacity in people with moderate to severe COPD [9, 10]. Therefore, supplemental oxygen may enable higher exercise intensity during an exercise training programme $[11,12]$ and is often provided for people with COPD during exercise training, especially those who desaturate during exercise [13]. However, there is limited evidence to support the provision of supplemental oxygen in clinical practice. Previous randomised trials comparing oxygen and air during exercise training have had small sample sizes [14-16], and included those on long-term oxygen therapy (LTOT) [15] and nondesaturators [11, 17]. Stronger evidence to support or refute the use of supplemental oxygen during pulmonary rehabilitation for people with COPD who are normoxaemic at rest but who desaturate during exercise is therefore required.

The aims of the study were to determine, in people with COPD who were normoxaemic at rest and desaturated during exercise, whether supplemental oxygen during exercise training was more effective than medical air (sham intervention) in: 1) improving endurance exercise capacity and HRQoL, and 2) improving peak walking capacity, reducing dyspnoea and increasing levels of daily physical activity. We hypothesised that those receiving oxygen would have greater increases in exercise capacity and HRQoL at completion of the exercise training programme than those receiving medical air.

\section{Methods}

This study was a prospective, multicentre, randomised controlled trial with concealed allocation, and blinding of participants, trainers and assessors. The full protocol has been published previously [18]. In brief, participants with a confirmed diagnosis of COPD on spirometry [19] with nadir $\mathrm{SpO}_{2}<90 \%$ from the better of two 6-min walk tests (6MWTs) performed on room air [20] were recruited from referrals to pulmonary rehabilitation at seven participating sites. The study was approved by the ethics committees of all participating sites and registered with the Australian New Zealand Clinical Trials Registry (identifier 12612000395831). Informed written consent was obtained from all participants.

Randomisation with stratification for study site, 6-min walk distance (6MWD) ( $\leqslant 350$ versus $>350 \mathrm{~m}$ ) and nadir $\mathrm{SpO}_{2}$ from the 6MWT (89-86\% versus <86\%) into an Oxygen group or Air group was by a central independent telephone randomisation system and only decoded at the completion of the statistical analyses. Participants, exercise trainers and assessors were blind to group allocation. Concentrators (5 L NewLife Elite Oxygen Concentrator; AirSep, Buffalo, NY, USA) were identical in appearance whether they delivered oxygen or air. Internal modification of the concentrator to deliver medical air for the Air group was undertaken by the supplier (Air Liquide Healthcare, Sydney, Australia) with approval from the

Affiliations: 'Discipline of Physiotherapy, Faculty of Health Sciences, The University of Sydney, Sydney, Australia. ${ }^{2}$ Sydney Local Health District, Sydney, Australia. ${ }^{3}$ Dept of Physiotherapy, Concord Repatriation General Hospital, Sydney, Australia. ${ }^{4}$ Discipline of Physiotherapy, School of Allied Health, LaTrobe University, Melbourne, Australia. ${ }^{5}$ Dept of Physiotherapy, Alfred Health, Melbourne, Australia. ${ }^{6}$ Institute for Breathing and Sleep, Melbourne, Australia. ${ }^{7}$ School of Physiotherapy and Exercise Science, Faculty of Health Sciences, Curtin University, Perth, Australia. ${ }^{8}$ Institute for Respiratory Health, Sir Charles Gairdner Hospital, Perth, Australia. ${ }^{9}$ School of Allied Health Sciences, Griffith University, Southport, Australia. ${ }^{10}$ Metro North Hospital and Health Service, The Prince Charles Hospital, Allied Health Research Collaborative, Brisbane, Australia. ${ }^{11}$ Dept of Physiotherapy, Sir Charles Gardiner Hospital, Perth, Australia. ${ }^{12}$ Dept of Physiotherapy, Royal Prince Alfred Hospital, Sydney, Australia. ${ }^{13}$ Dept of Physiotherapy, Austin Health, Melbourne, Australia. ${ }^{14}$ Dept of Physiotherapy, Monash University, Melbourne, Australia. ${ }^{15}$ Dept of Physiotherapy, Prince Charles Hospital, Queensland, Australia. ${ }^{16}$ Dept of Respiratory and Sleep Medicine, Austin Health, Melbourne, Australia.

Correspondence: Jennifer A. Alison, Discipline of Physiotherapy, Faculty of Health Sciences, The University of Sydney, 75 East Street, Lidcombe, NSW 2141, Australia. E-mail: jennifer.alisondasydney.edu.au 
Therapeutic Goods Administration, Australia, and the code was only available to the randomisation centre. Both groups received gas flow of $5 \mathrm{~L} \cdot \mathrm{min}^{-1}$ via nasal prongs during exercise training.

Exercise training for both groups initially consisted of $20 \mathrm{~min}$ of treadmill walking at $80 \%$ of the average 6MWT speed and $10 \mathrm{~min}$ of stationary cycling at $60 \%$ of the peak work rate, estimated from the 6MWT [21], supervised three times per week for 8 weeks. Exercise duration was progressed up to a total of $40 \mathrm{~min}$ (20 min treadmill walking and 20 min stationary cycling) by week 3 . Throughout the training programme, work rate (intensity) was increased according to symptoms so that dyspnoea or rate of perceived exertion (RPE) was at a "moderate" to "somewhat severe" level (i.e. a score of 3-4 on the modified dyspnoea and RPE 0-10 scales) [22].

$\mathrm{SpO}_{2}$ was monitored during one training session each week by a clinician independent of the study and blind to group allocation. The $\mathrm{SpO}_{2}$ level was not revealed to the trainer and training was interrupted only if $\mathrm{SpO}_{2}$ fell to $<80 \%$ [23]. The participant was asked to recommence exercising when $\mathrm{SpO}_{2}$ returned to $88 \%$. The independent clinician recorded the duration of exercise and rests, which was reproduced by the trainer for the remainder of the sessions in that week.

At the end of the exercise training programme participants were provided with an education booklet and an individualised home maintenance exercise programme. No domiciliary supplemental oxygen was provided during the training or in the 6-month home programme.

\section{Outcome measures}

The primary outcomes were endurance exercise capacity measured by the endurance shuttle walk test (ESWT) [24] and HRQoL measured by the Chronic Respiratory Disease Questionnaire (CRQ)-Total score [25]. The secondary outcomes were peak exercise capacity measured by the incremental shuttle walk test (ISWT) [26], the domain scores of the CRQ (i.e. Dyspnoea, Fatigue, Emotional Function and Mastery), severity and impact of dyspnoea using the Dyspnoea-12 Questionnaire [27] (in which a lower score indicates less dyspnoea), and physical activity levels measured by a multisensor activity monitor (SenseWear MF; BodyMedia, Pittsburgh, PA, USA) worn for 7 days. The minimum wear time for inclusion of physical activity data was set at 3 days for at least $20 \mathrm{~h}$ per day. All outcome measures were taken at baseline, at the completion of exercise training and 6 months following completion of the exercise training programme. The ESWT and ISWT were performed twice at each of these measurement time-points.

\section{Sample size calculation}

It was estimated that 110 participants were needed to ensure that 88 participants completed the study, allowing for a $20 \%$ loss to follow-up. This sample size was sufficient to provide $80 \%$ power to detect as significant, at the (two-sided) 5\% level, a minimum $156 \mathrm{~s}$ difference [28] in the mean ESWT time between the Oxygen group and the Air group, assuming a standard deviation of $250 \mathrm{~s}$ for the ESWT [29] and to detect a minimum 0.5 point difference [30] in the mean CRQ-Total points per item between the groups, assuming a standard deviation of 0.85 points per item [31].

\section{Data analysis}

The exercise training dose that each participant achieved was calculated from the product of the training intensity and exercise duration [32]. The training intensity was estimated using the American College of Sports Medicine equations for walking and leg cycling [33], expressed as metabolic equivalents (METs). For walking, the training dose calculation included speed, grade and session duration, and for cycling included power and session duration. Training dose was then expressed as METs completed per session for each participant.

Data were analysed using SPSS version 22 (IBM, Armonk, NY, USA) on an intention-to-treat basis. Differences between groups for change over time were analysed using linear mixed models. Models included intervention group, time (i.e. data collection time-points of baseline, end-training and 6 months after completion of training), group xtime interaction and random effect. Baseline values were included as a covariate. Uncertainty regarding the mean between-group differences was quantified with 95\% confidence intervals. Baseline and end-training dyspnoea and RPE from the ESWT were compared at isotime, defined as the end time of the shortest test used in the analysis. Participants who completed a minimum of 16 training sessions (66\% of total sessions) were included in a per-protocol analysis using the same methods as the primary analysis.

\section{Results}

Participant flow and characteristics

111 participants were recruited, with 58 randomised to the Oxygen group and 53 to the Air group (figure 1). Participants, on average, had severe COPD (mean \pm SD FEV1 $46 \pm 17 \%$ predicted and FEV1/FVC 


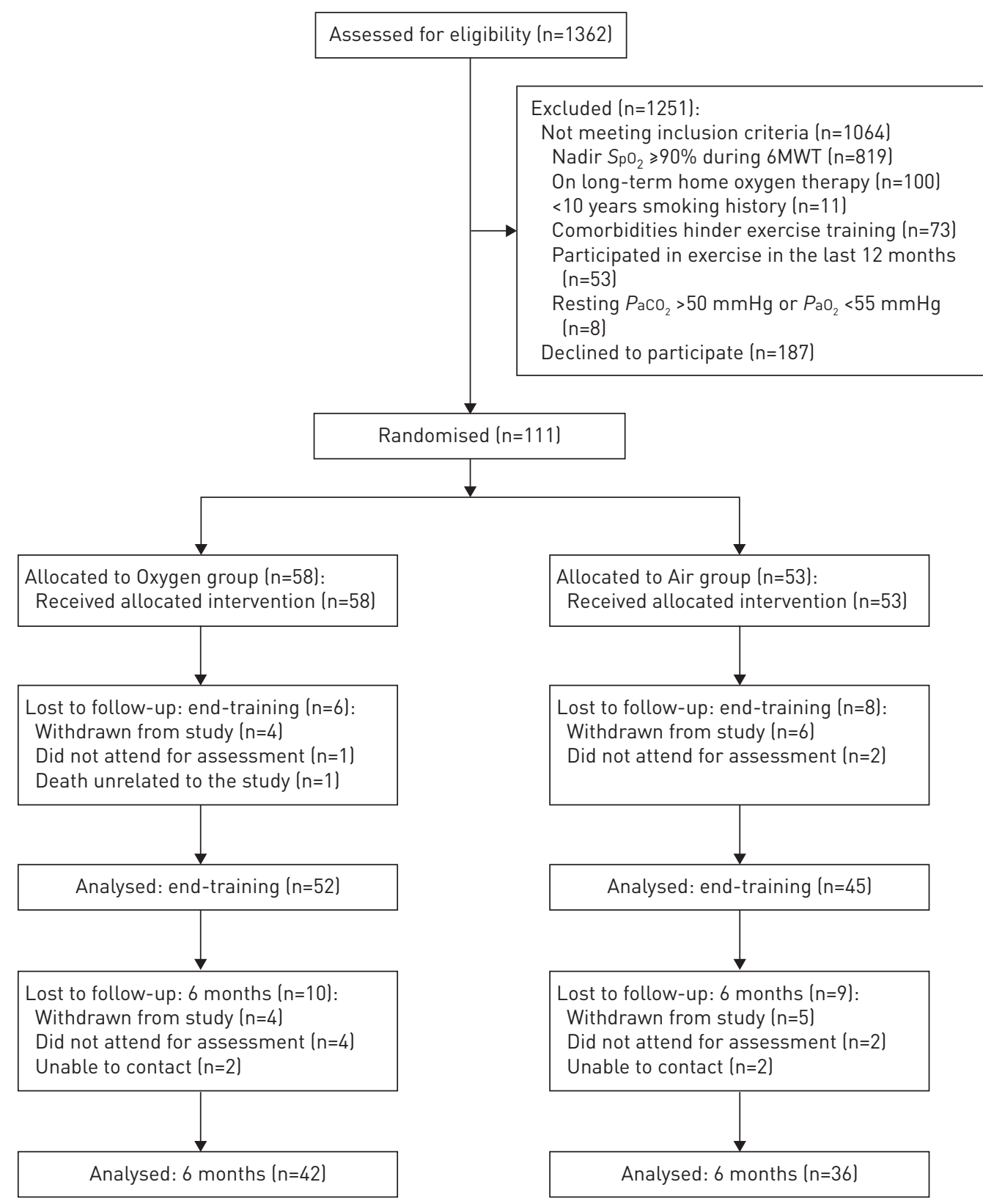

FIGURE 1 Flow of participants through the trial. $\mathrm{SpO}_{2}$ : oxygen saturation measured by pulse oximetry; $6 \mathrm{MWT}$ : 6-min walk test; $P_{\mathrm{aCO}_{2}}$ : arterial carbon dioxide tension; $\mathrm{PaO}_{2}$ : arterial oxygen tension.

ratio $0.43 \pm 0.13$ ) (table 1). At baseline, both the Oxygen and Air groups were similar for lung function, arterial blood gases and 6MWD. The baseline, end-training and 6-month follow-up values for all outcomes for both the Oxygen and Air groups are reported in table 2.

\section{Primary outcomes}

For the change in ESWT time, there was no between-group difference at end-training (table 3 and figure 2a). Within-group analyses at end-training showed significant improvements in ESWT time in both the Oxygen and Air groups (table 3). There was no between-group difference in the change in CRQ-Total score at end-training (table 3 and figure $2 \mathrm{~b}$ ). Within-group analyses at end-training showed that both the Oxygen and Air groups had significant improvements in CRQ-Total (table 3).

At 6-month follow-up, there were no between-group differences in change in ESWT time or CRQ-Total score (table 3, and figure $2 \mathrm{a}$ and $\mathrm{b}$ ). Within-group analyses showed nonsignificant improvements in ESWT from baseline to 6-month follow-up in both the Oxygen and Air groups. There were significant within-group increases in CRQ-Total from baseline to 6-month follow-up in both the Oxygen and Air groups (table 3). 


\section{TABLE 1 Participant characteristics}

Oxygen group Air group Loss to follow-up at end-training

\begin{tabular}{|c|c|c|c|}
\hline Subjects & 58 & 53 & 14 \\
\hline Age years & $69 \pm 7$ & $69 \pm 8$ & $65 \pm 8$ \\
\hline Male/female & $30 / 28$ & $31 / 22$ & $8 / 6$ \\
\hline BMI $\mathrm{kg} \cdot \mathrm{m}^{-2}$ & $27 \pm 6$ & $29 \pm 7$ & $29 \pm 8$ \\
\hline Current smoker & 2 (3) & $4(8)$ & $0(0)$ \\
\hline \multicolumn{4}{|l|}{ Pulmonary function } \\
\hline $\mathrm{FEV}_{1} \mathrm{~L}$ & $1.2 \pm 0.4$ & $1.2 \pm 0.5$ & $1.1 \pm 0.2$ \\
\hline FEV $1 \%$ pred & $47 \pm 17$ & $45 \pm 16$ & $42 \pm 8$ \\
\hline FVC L & $2.9 \pm 1.0$ & $2.9 \pm 0.9$ & $2.8 \pm 0.7$ \\
\hline FVC \% pred & $83 \pm 19$ & $79 \pm 15$ & $78 \pm 14$ \\
\hline FEV $1 / F V C \%$ & $42 \pm 11$ & $43 \pm 14$ & $41 \pm 9$ \\
\hline RV/TLC \% & $55 \pm 9$ & $54 \pm 10$ & $54 \pm 7$ \\
\hline Dıco \% pred & $48 \pm 17$ & $50 \pm 16$ & $57 \pm 21$ \\
\hline \multicolumn{4}{|l|}{ GOLD grade } \\
\hline I & $2(3)$ & $1(2)$ & $0(0)$ \\
\hline$\|$ & $16(28)$ & $18(34)$ & $3(21)$ \\
\hline III & $31(53)$ & $24(45)$ & $10(71)$ \\
\hline IV & $9(16)$ & $10(19)$ & $1(8)$ \\
\hline \multicolumn{4}{|l|}{ Arterial blood gases (room air) } \\
\hline $\mathrm{pH}$ & $7.4 \pm 0.03$ & $7.4 \pm 0.04$ & $7.4 \pm 0.02$ \\
\hline $\mathrm{PaO}_{2} \mathrm{mmHg}$ & $70.5 \pm 10$ & $73.9 \pm 12$ & $73.0 \pm 7$ \\
\hline $\mathrm{PaCO}_{2} \mathrm{mmHg}$ & $37.8 \pm 5$ & $37.5 \pm 4$ & $40.8 \pm 5$ \\
\hline $\mathrm{SaO}_{2} \%$ & $94 \pm 4$ & $94 \pm 2$ & $94 \pm 2$ \\
\hline $\mathrm{SpO}_{2}$ nadir $\%$ & $85 \pm 4$ & $85 \pm 4$ & $86 \pm 3$ \\
\hline 6MWD m & $401 \pm 108$ & $402 \pm 97$ & $414 \pm 100$ \\
\hline CRQ-Dyspnoea average score baseline & $3.2 \pm 1$ & $2.9 \pm 1$ & $3.2 \pm 1$ \\
\hline Dyspnoea-12 score baseline & $15 \pm 9$ & $17 \pm 9$ & $16 \pm 7$ \\
\hline \multicolumn{4}{|l|}{ Comorbidities } \\
\hline Hypertension & $14(24)$ & $26(49)$ & $7(50)$ \\
\hline Cardiac (including previous surgery) & $14(24)$ & $19(36)$ & $4(29)$ \\
\hline Diabetes & $11(19)$ & $5(9)$ & $2(14)$ \\
\hline Bronchiectasis & $2(3)$ & $5(9)$ & $2(14)$ \\
\hline Other respiratory history & $4(7)$ & $8(15)$ & $1(7)$ \\
\hline Cancer history & $8(15)$ & $4(8)$ & $2(14)$ \\
\hline Neurological & $3(5)$ & $4(8)$ & $2(14)$ \\
\hline Psychological & $2(3)$ & $8(15)$ & $2(14)$ \\
\hline Increased cholesterol & $14(24)$ & $10(19)$ & $4(29)$ \\
\hline Musculoskeletal & 19 (33) & $19(36)$ & $4(29)$ \\
\hline
\end{tabular}

Data are presented as $\mathrm{n}$, mean \pm SD or $\mathrm{n}(\%)$. BMI: body mass index; $F E V_{1}$ : forced expiratory volume in $1 \mathrm{~s}_{\text {; }}$ FVC: forced vital capacity; RV: residual volume; TLC: total lung capacity; DLCO: diffusing capacity of the lung for carbon monoxide; GOLD: Global Initiative for Chronic Obstructive Lung Disease; $\mathrm{PaO}_{2}$ : arterial oxygen tension; $\mathrm{PaCO}_{2}$ : arterial carbon dioxide tension; $\mathrm{SaO}_{2}$ : arterial oxygen saturation; $\mathrm{SpO}_{2}$ : oxygen saturation measured by pulse oximetry; 6MWD: 6-min walk distance; CRQ: Chronic Respiratory Disease Questionnaire.

\section{Secondary outcomes}

There was no between-group difference in the change in incremental shuttle walk distance (ISWD) at end-training (table 3). The within-group analysis at end-training showed significant improvements in ISWD in both the Oxygen and Air groups (table 3). There were no between-group differences in the change in any CRQ domain scores at end-training (table 3). There were significant within-group improvements at end-training in both the Oxygen and Air groups in CRQ-Dyspnoea, CRQ-Fatigue and CRQ-Mastery, with the improvements in CRQ-Dyspnoea and CRQ-Fatigue exceeding the minimum clinically important difference (MCID) of 0.5 points [34] in both groups (table 3). CRQ-Emotional Function was only significantly improved in the Oxygen group at end-training.

There were no between-group differences in change in Dyspnoea-12 scores at end-training. Significant within-group improvements in Dyspnoea-12 Total and Dyspnoea-12 Physical were only evident in the Oxygen group (table 3). For change in physical activity, there were no significant between-group or within-group differences at end-training in any physical activity outcomes (table 3 ). 
TABLE 2 Exercise capacity, health-related quality of life, Dyspnoea-12 and physical activity at baseline, end-training and 6-month follow-up

\begin{tabular}{|c|c|c|c|c|c|c|}
\hline & \multicolumn{2}{|c|}{ Baseline } & \multicolumn{2}{|c|}{ End-training } & \multicolumn{2}{|c|}{ 6-month follow-up } \\
\hline \multicolumn{7}{|l|}{ ESWT } \\
\hline Subjects & 58 & 53 & 51 & 44 & 38 & 36 \\
\hline Time s & $327 \pm 191$ & $319 \pm 139$ & $500 \pm 361$ & $456 \pm 308$ & $423 \pm 307$ & $423 \pm 328$ \\
\hline Subjects & 51 & 44 & 51 & 44 & & \\
\hline Dyspnoea isotime score ${ }^{\#}$ & $4.3 \pm 1.8$ & $4.8 \pm 1.7$ & $3.3 \pm 1.7$ & $3.7 \pm 1.7$ & & \\
\hline Subjects & 58 & 53 & 50 & 44 & 39 & 36 \\
\hline Distance $\mathrm{m}$ & $287 \pm 121$ & $285 \pm 124$ & $326 \pm 128$ & $304 \pm 132$ & $335 \pm 137$ & $311 \pm 124$ \\
\hline Subjects & 50 & 43 & 50 & 43 & & \\
\hline Dyspnoea isotime score & $3.4 \pm 1.6$ & $3.6 \pm 1.7$ & $2.6 \pm 1.4$ & $3.2 \pm 1.4$ & & \\
\hline \multicolumn{7}{|l|}{ CRQ } \\
\hline Subjects & 58 & 53 & 52 & 45 & 42 & 36 \\
\hline Mastery PPI & $5.0 \pm 1.2$ & $5.0 \pm 1.4$ & $5.3 \pm 1.2$ & $5.4 \pm 1.2$ & $5.5 \pm 1.1$ & $5.2 \pm 1.3$ \\
\hline \multicolumn{7}{|l|}{ Dyspnoea-12 } \\
\hline Subjects & 58 & 53 & 52 & 45 & 42 & 36 \\
\hline Total score & $15 \pm 9$ & $17 \pm 9$ & $13 \pm 9$ & $17 \pm 9$ & $14 \pm 8$ & $17 \pm 9$ \\
\hline Physical score & $11 \pm 6$ & $12 \pm 6$ & $9 \pm 5$ & $11 \pm 6$ & $10 \pm 5$ & $12 \pm 5$ \\
\hline Affective score & $5 \pm 4$ & $5 \pm 5$ & $4 \pm 4$ & $5 \pm 5$ & $5 \pm 4$ & $5 \pm 5$ \\
\hline \multicolumn{7}{|l|}{ Physical activity } \\
\hline Subjects & 56 & 47 & 48 & 39 & 36 & 29 \\
\hline Steps·day ${ }^{-1}$ & $3032 \pm 2074$ & $3158 \pm 2374$ & $3138 \pm 2225$ & $2903 \pm 2002$ & $3215 \pm 2172$ & $3852 \pm 2915$ \\
\hline Total EE·day ${ }^{-1}$ kcal & $2089 \pm 421$ & $2195 \pm 459$ & $2037 \pm 401$ & $2247 \pm 418$ & $2079 \pm 414$ & $2214 \pm 545$ \\
\hline Sedentary $^{+}$min $\cdot$ day $^{-1}$ & $731 \pm 163$ & $785 \pm 154$ & $756 \pm 146$ & $775 \pm 172$ & $738 \pm 169$ & $760 \pm 160$ \\
\hline Light activity ${ }^{\S} \min \cdot$ day $^{-1}$ & $215 \pm 128$ & $180 \pm 107$ & $176 \pm 102$ & $159 \pm 84$ & $210 \pm 135$ & $193 \pm 97$ \\
\hline \multicolumn{7}{|c|}{$\begin{array}{l}\text { Data are presented as } n \text { or mean } \pm \text { SD. ESWT: endurance shuttle walk test; RPE: rate of physical exertion; ISWT: incremental shuttle walk test; } \\
\text { CRQ: Chronic Respiratory Disease Questionnaire; PPI: points per item; EE: energy expenditure; MET: metabolic equivalent. }{ }^{\#} \text { : ESWT dyspnoea } \\
\text { isotime score: comparison of dyspnoea scores at the end time of the shortest ESWT; }{ }^{\uparrow} \text { : ISWT dyspnoea isotime score: comparison of dyspnoea } \\
\text { scores at the end time of the shortest ISWT; }{ }^{+} \text {: sedentary: awake time spent METs }<1.5 ;{ }^{\S} \text { : light activity: time spent METs } 1.5-<3 ;{ }^{f}: \text { moderate } \\
\text { activity: time spent METs } 3-<6 ;{ }^{\# \#} \text { : vigorous activity: time spent METs } \geqslant 6 \text {. }\end{array}$} \\
\hline
\end{tabular}

There were no significant between-group differences in change in dyspnoea or RPE at isotime in the ESWT. Within-group analyses showed that dyspnoea and RPE were significantly lower at ESWT isotime in both the Oxygen and Air groups at end-training (table 3).

There were no between-group differences in the change in any secondary outcomes from baseline to 6-month follow-up (table 3). Within-group changes in the Oxygen group showed a significant increase in ISWD and significantly greater scores in CRQ-Dyspnoea, CRQ-Fatigue and CRQ-Mastery from baseline to 6-month follow-up (table 3). In the Air group, CRQ-Total, CRQ-Dyspnoea and CRQ-Emotional Function were significantly greater from baseline to 6-month follow-up (table 3).

\section{Exercise training}

During the exercise training programme, both groups increased the training dose per session for treadmill and cycle training (figure 3). There was no between-group difference in mean training dose over the 24 training sessions for treadmill exercise (mean difference 2.2 total METs (95\% CI -5.0-9.3 total METs) favouring the Oxygen group). For cycle exercise, the Oxygen group had a significantly greater mean training dose than the Air group (mean difference 4.1 total METs (95\% CI 0.2-8.0 total METs)).

Data collected by the independent clinician showed that mean $\mathrm{SpO}_{2}$ for each group in the last 5 min of the 20-min training session for treadmill and cycle exercise was significantly higher in the Oxygen group than the Air group (mean difference 5\% (95\% CI 4-6\%) for treadmill exercise and mean difference 3\% (95\% CI 
TABLE 3 Within-group and between-group statistical analyses

Within-group difference from baseline

\begin{tabular}{|c|c|c|c|c|c|c|}
\hline & \multirow{2}{*}{\multicolumn{2}{|c|}{ Oxygen group }} & \multirow{2}{*}{\multicolumn{2}{|c|}{ Air group }} & \multirow{2}{*}{\multicolumn{2}{|c|}{ (Oxygen group-Air group) }} \\
\hline & & & & & & \\
\hline & End-training & 6-month follow-up & End-training & 6-month follow-up & End-training & 6-month follow-up \\
\hline \multicolumn{7}{|l|}{ ESWT } \\
\hline Time s & $162(80-244)^{*}$ & $76(-16-169)$ & $147(59-235)^{*}$ & $91(-4-187)$ & $15(-106-136)$ & $-15(-148-118)$ \\
\hline Dyspnoea isotime score ${ }^{\#}$ & $-1.2(-1.6--0.8)^{*}$ & & $-0.9(-1.4--0.4)^{*}$ & & $-0.3(-0.3-0.9)$ & \\
\hline RPE isotime score & $-1.2(-1.7--0.7)^{*}$ & & $-1.1(-1.6--0.5)^{*}$ & & $-0.2(-0.6-0.9)$ & \\
\hline \multicolumn{7}{|l|}{ ISWT } \\
\hline Distance $\mathrm{m}$ & $33(20-47)^{*}$ & $24(9-39) *$ & $28(13-42)^{*}$ & $15(-1-30)$ & $5(-14-25)$ & $9(-12-31)$ \\
\hline Dyspnoea isotime score ${ }^{\Uparrow}$ & $-0.9(-1.2--0.5)^{*}$ & & $-0.3(-0.7-0.1)$ & & $-0.6(-1.2--0.1)^{* *}$ & \\
\hline \multicolumn{7}{|l|}{ CRQ } \\
\hline Total PPI & $0.4(0.2-0.7)^{*}$ & $0.3(0.1-0.5)^{*}$ & $0.4(0.2-0.7)^{*}$ & $0.4(0.1-0.6)^{*}$ & $0.0(-0.3-0.3)$ & $-0.0(-0.4-0.3)$ \\
\hline Dyspnoea PPI & $0.7(0.4-1.0)^{*}$ & $0.6(0.3-0.9)^{*}$ & $0.6(0.3-0.9)^{*}$ & $0.6(0.3-0.9)^{*}$ & $0.1(-0.3-0.5)$ & $0.004(-0.5-0.5)$ \\
\hline Fatigue PPI & $0.6(0.3-0.9)^{*}$ & $0.3(0.01-0.7)^{*}$ & $0.5(0.2-0.9)^{*}$ & $0.3(-0.01-0.7)$ & $0.03(-0.4-0.5)$ & $-0.01(-0.5-0.5)$ \\
\hline Emotional Function PPI & $0.4(0.1-0.6)^{*}$ & $0.2(-0.0-0.5)$ & $0.2(-0.0-0.5)$ & $0.3(0.01-0.6)^{*}$ & $0.2(-0.2-0.5)$ & $-0.1(-0.4-0.3)$ \\
\hline Mastery PPI & $0.3(0.0-0.5)^{*}$ & $0.3(0.0-0.6) *$ & $0.3(0.1-0.6)^{*}$ & $0.1(-0.2-0.4)$ & $-0.1(-0.5-0.3)$ & $0.2(-0.2-0.6)$ \\
\hline \multicolumn{7}{|l|}{ Dyspnoea-12 } \\
\hline Total score & $-2.3(-4.0--0.5)^{*}$ & $-0.7(-2.6-1.2)$ & $-0.3(-2.2-1.6)$ & $0.2(-1.8-2.3)$ & $-1.9(-4.5-0.7)$ & $-0.9(-3.7-1.9)$ \\
\hline Physical score & $-1.5(-2.7--0.4)^{*}$ & $-0.5(-1.8-0.7)$ & $-0.3(-1.6-0.9)$ & $0.7(-0.7-2.0)$ & $-1.2(-2.9-0.5)$ & $-1.2(-3.1-0.6)$ \\
\hline Affective score & $-0.8(-1.6-0.1)$ & $-0.2(-1.2-0.7)$ & $0.1(-0.8-1.0)$ & $-0.4(-1.4-0.6)$ & $-0.9(-2.2-0.4)$ & $0.2(-1.2-1.6)$ \\
\hline \multicolumn{7}{|l|}{ Physical activity } \\
\hline Steps.day ${ }^{-1}$ & $57(-277-391)$ & $146(-233-524)$ & $-283(-654-87)$ & $462(34-889)^{*}$ & $340(-157-839)$ & $-316(-887-255)$ \\
\hline Total EE·day ${ }^{-1}$ kcal & $-35(-109-40)$ & $-55(-139-29)$ & $24(-58-107)$ & $-51(-147-45)$ & $-59(-171-53)$ & $-4(-132-125)$ \\
\hline Sedentary $^{+} \min \cdot$ day $^{-1}$ & $7(-24-38)$ & $12(-23-46)$ & $-10(-44-25)$ & $-13(-52-26)$ & $16(-30-63)$ & $25(-27-77)$ \\
\hline Light activity $^{\S} \min \cdot$ day $^{-1}$ & $-27(-47--8)$ & $-1(-23-22)$ & $-21(-43-1)$ & $8(-17-34)$ & $-6(-36-24)$ & $-9(-43-25)$ \\
\hline Moderate activity ${ }^{f}$ min $\cdot$ day $^{-1}$ & $3(-3-8)$ & $-3(-9-3)$ & $-0(-6-6)$ & $-1(-8-6)$ & $3(-6-11)$ & $-2(-11-8)$ \\
\hline Vigorous activity $^{\# \#}$ min.day ${ }^{-1}$ & $-1(-2-1)$ & $-1(-3--0)$ & $0(-1-1)$ & $-1(-2-1)$ & $-1(-2-1)$ & $-1(-3-1)$ \\
\hline
\end{tabular}

Between-group difference (Oxygen group-Air group)

Data are presented as mean $(95 \% \mathrm{CI})$ adjusted for baseline values. ESWT: endurance shuttle walk test; RPE: rate of physical exertion; ISWT: incremental shuttle walk test; CRQ: Chronic Respiratory Disease Questionnaire; PPI: points per item; EE: energy expenditure; MET: metabolic

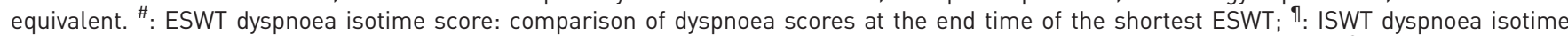
score: comparison of dyspnoea scores at the end time of the shortest ISWT; ${ }^{+}$: sedentary: awake time spent METs <1.5; ${ }^{\S}$ : light activity: time spent METs $1.5-<3 ; f^{f}$ moderate activity: time spent METs $3-<6$; \#\#: vigorous activity: time spent METs $\geqslant 6$. *: significant within-group difference from baseline; ${ }^{* *}$ : significant between-group difference.

1-4\%) for cycle exercise (table 4). Exercise training was only interrupted in four participants for $\mathrm{SpO}_{2}$ $<80 \%$, one in the Oxygen group and three in the Air group, and none were interrupted during cycle training. The mean dyspnoea and RPE scores during training were 3-4 ("moderate" to "somewhat severe") at each training session for both the Oxygen and Air groups (supplementary table S1). Dyspnoea and RPE scores were significantly higher in the Air group than the Oxygen group during treadmill training. RPE scores were significantly higher in the Air group than the Oxygen group during cycle training (supplementary table S1). Spirometric indices remained stable over the 8 months of the study (supplementary table S2).
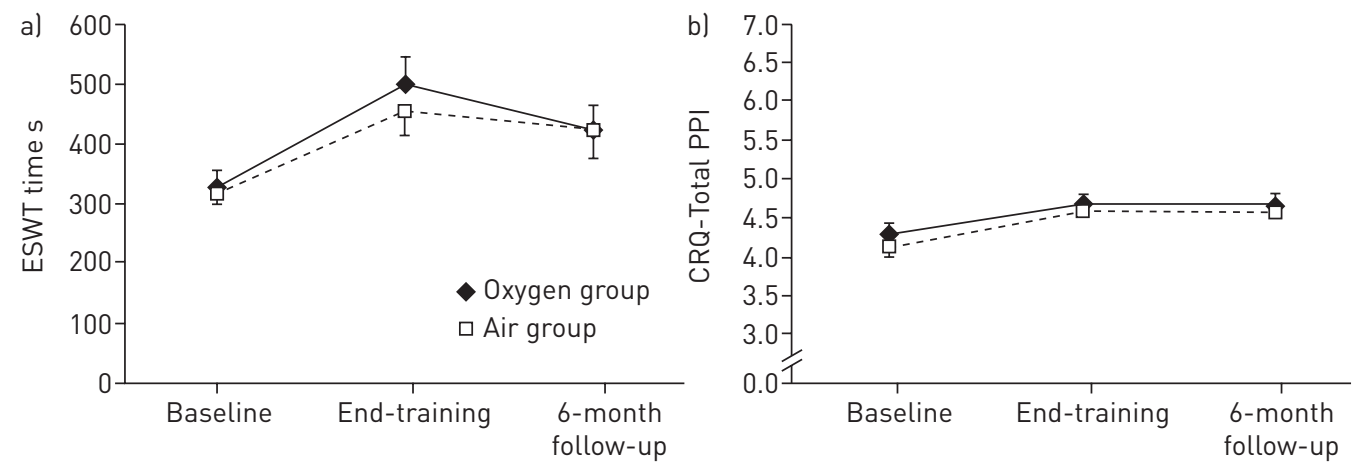

FIGURE 2 Change in al endurance shuttle walk test (ESWT) time and b) Chronic Respiratory Disease Questionnaire (CRQ)-Total in the Oxygen and Air groups. PPI: points per item. Data are presented as mean \pm SE. 

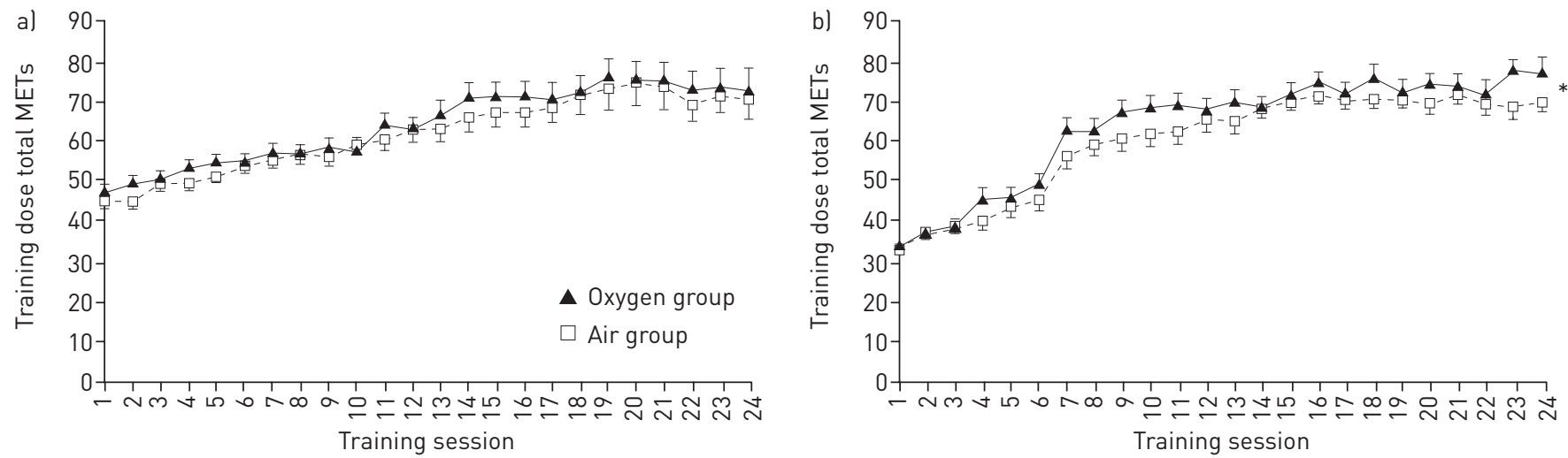

FIGURE 3 Training dose (durationxmetabolic equivalents (METs)) per training session for a) treadmill exercise and b) cycle exercise in Oxygen and Air groups. Data are presented as mean \pm SE. *: $p<0.05$.

The incidence and severity of adverse events were similar in both groups. In the Oxygen group, one participant developed atrial fibrillation during a training session, one had a syncopal episode on the way to a training session and there was one death unrelated to the study. In the Air group, one participant had a mild stroke after finishing a treadmill training session and one participant had a minor heart attack on a nontraining day.

\section{Per-protocol analyses}

89 participants (48 in the Oxygen group and 41 in the Air group) attended at least 16 training sessions and therefore met the criteria for inclusion in per-protocol analyses (supplementary tables S3-S5). Similar to the results of the intention-to-treat analyses, there were no between-group differences in changes from baseline in any of the outcomes at end-training or at 6-month follow-up. There were significant within-group changes in exercise capacity and HRQoL in both groups (supplementary table S5).

\section{Discussion}

Supplemental oxygen used during an 8-week supervised exercise training programme resulted in no greater improvements in endurance exercise capacity or HRQoL than did medical air in people with COPD who desaturated during a 6MWT. Importantly, both the Oxygen and Air groups achieved benefits after exercise training, with significant increases in both exercise capacity and HRQoL as would be expected in an effective exercise training programme in people with COPD [1].

Our results augment those of previous studies that compared exercise training with supplemental oxygen or air but which had less methodological rigour, including lack of blinding [2, 14-16, 35], small sample sizes [14-16], higher $\mathrm{SpO}_{2}$ criteria for stopping exercise (e.g. exercise training stopped if $\mathrm{SpO}_{2}$ fell to $<90 \%$ ) $[14,16]$, training sessions of short duration [15], inclusion of participants on LTOT [15] or provision of oxygen for home exercise [2], all of which impact the interpretation of findings. However, as in our study, most previous studies reported no significant between-group differences in exercise capacity [2, 14-16] or HRQoL $[2,14,15]$ at the end of an exercise training period where participants used either supplemental oxygen or air during training. One study reported a significantly greater walk distance after training in an oxygen group compared to an air group; however, the outcome exercise test was performed on oxygen in the Oxygen group and on air in the Air group, making the significant between-group difference difficult to interpret [35].

TABLE 4 Oxygen saturation measured by pulse oximetry $\left(\mathrm{SpO}_{2}\right)$ during treadmill and cycle exercise training

Oxygen group

\section{Treadmill $\mathrm{SpO}_{2} \%$}

Cycle $\mathrm{SpO}_{2} \%$

$94 \pm 3$
$94 \pm 3$

Air group

$89 \pm 4$

$92 \pm 3$
Between-group difference (Oxygen group-Air group)

Data are presented as mean \pm SD weekly measures of $\mathrm{SpO}_{2}$ in all participants in the last 5 min of the 20 -min treadmill and cycle exercise training, unless otherwise stated. ${ }^{\#}$ : mean $(95 \% \mathrm{CI})$. 
Based on the acute physiological responses to oxygen during exercise in people with moderate to severe COPD $[8,9,36]$ it might have been expected that the Oxygen group would have been able to train at a higher intensity than the Air group, and that this would confer greater improvements in exercise capacity [32]. However, during treadmill training the Oxygen group was not able to achieve a greater training dose per session than the Air group despite a significantly higher measured $\mathrm{SpO}_{2}$ and significantly lower dyspnoea and RPE scores during treadmill training sessions. This was likely the reason for an absence of between-group differences in change in exercise capacity measured by a walking test at end-training. The fact that a higher $\mathrm{SpO}_{2}$ did not confer greater training benefits in the Oxygen group may be due to the large physiological stimulus applied to both groups (i.e. training three times per week for 8 weeks at an increasing exercise dose). This training stimulus likely overwhelmed the small physiological advantage of acute oxygen administration that would have been expected to favour the Oxygen group.

Importantly, both the Oxygen and Air groups achieved the benefits in exercise capacity and HRQoL that would be expected from an exercise training programme in people with COPD [1], with reductions in CRQ-Dyspnoea and CRQ-Fatigue that met or exceeded the MCID of 0.5 points [34] in both groups at end-training. Such findings show that the exercise training programme was sufficiently intense to elicit improvements in this specific group of patients who desaturated during exercise and that these improvements could be achieved without supplemental oxygen. At 6-month follow-up the improvement in CRQ-Dyspnoea in both groups still exceeded the MCID, demonstrating a strong effect of exercise training in both groups on this important patient-reported outcome. Although there were improvements in exercise capacity in both groups, these did not translate into increases in physical activity in either group. This finding is consistent with a recent systematic review that found little evidence that exercise training improves daily physical activity levels in people with COPD [37].

This was a large, rigorously blinded, randomised controlled trial of oxygen versus air during training in COPD, in which the exercise training programme was representative of programmes commonly provided in pulmonary rehabilitation [38], participants were not stopped due to desaturation and in which the primary outcome measure, i.e. the ESWT, was reflective of daily life. Such features make the study methods and findings applicable to most pulmonary rehabilitation programmes. The loss to follow-up at end-training was small (13\%), further strengthening these findings. However, there were a number of limitations. While stratification by minimisation was used for variables of $6 \mathrm{MWD}$ and nadir $\mathrm{SpO}_{2}$ to ensure equivalence of groups at baseline, the acute response to oxygen supplementation was not evaluated. Therefore, there may have been an imbalance between the groups of oxygen responders (i.e. those who increase exercise performance while breathing oxygen) and nonresponders [39]. As no baseline characteristics have been shown to predict oxygen response [40], it was not possible retrospectively to determine whether groups were similar for this variable. Nonetheless, randomisation should have ensured a similar number of oxygen responders in both groups. Since the study was not powered to evaluate the effects of oxygen supplementation compared to medical air during training in people with severe oxygen desaturation (i.e. $\mathrm{SpO}_{2} \leqslant 80 \%$ during a $6 \mathrm{MWT}$ ) the findings cannot be generalised to this group, or to those prescribed LTOT, those with other lung diseases such as interstitial lung disease or those with pulmonary hypertension.

In summary, this large randomised controlled trial with blinding of participants, trainers and assessors found that both Oxygen and Air groups significantly improved exercise capacity and HRQoL with no greater benefit from training with supplemental oxygen than with medical air. The clinical implication from this study is that supplemental oxygen to correct oxygen desaturation is not required for patients to benefit from exercise training. Thus, for people with COPD, who are normoxaemic at rest but who desaturate during exertion, exercise training programmes could be provided in venues where supplemental oxygen is not available, enabling pulmonary rehabilitation programmes to be more widely accessible in the community.

Acknowledgements: The authors wish to acknowledge Jennifer K. Peat (Australian Catholic University, Sydney, Australia) for statistical support.

Conflict of interest: J.A. Alison reports grants from National Health and Medical Research Council, Australia, during the conduct of the study. Z.J. McKeough reports grants from National Health and Medical Research Council, Australia, during the conduct of the study. R.W.M. Leung reports grants and personal fees from National Health and Medical Research Council, Australia, during the conduct of the study. A.E. Holland reports grants from National Health and Medical Research Council, Australia, during the conduct of the study. K. Hill reports grants from National Health and Medical Research Council, Australia, during the conduct of the study; personal fees for lecturing from Menarini Australia, personal fees for meeting attendance from Journal of Physiotherapy, grants from Better Breathing Foundation, personal fees (royalties) from SLACK publishing, outside the submitted work. N.R. Morris reports grants from National Health and Medical Research Council, Australia, during the conduct of the study. S. Jenkins reports grants from National Health and Medical Research Council, Australia, during the conduct of the study. L.M. Spencer reports grants from National Health and Medical Research Council, Australia, during the conduct of the study. C.J. Hill reports grants from National Health 
and Medical Research Council, Australia, during the conduct of the study. A.L. Lee reports grants from National Health and Medical Research Council, Australia, during the conduct of the study. H. Seale reports grants from National Health and Medical Research Council, Australia, during the conduct of the study. N. Cecins reports grants from National Health and Medical Research Council, Australia, during the conduct of the study. C.F. McDonald reports personal fees from Pfizer, GSK and Novartis, institutional fees for lecturing from Menarini, outside the submitted work.

Support statement: The study was funded by a National Health and Medical Research Council, Australia, project grant APP1019989. Funding information for this article has been deposited with the Crossref Funder Registry.

\section{References}

1 McCarthy B, Casey D, Devane D, et al. Pulmonary rehabilitation for chronic obstructive pulmonary disease. Cochrane Database Syst Rev 2015; 2: CD003793.

2 Ringbaek T, Martinez G, Lange P. The long-term effect of ambulatory oxygen in normoxaemic COPD patients: a randomised study. Chron Respir Dis 2013; 10: 77-84.

3 Jenkins S, Cecins N. Six-minute walk test: observed adverse events and oxygen desaturation in a large cohort of patients with chronic lung disease. Intern Med J 2011; 41: 416-422.

4 Spruit MA, Singh SJ, Garvey C, et al. An official American Thoracic Society/European Respiratory Society statement: key concepts and advances in pulmonary rehabilitation. Am J Respir Crit Care Med 2013; 188: e13-e64.

5 Casaburi R, Patessio A, Ioli F, et al. Reductions in exercise lactic acidosis and ventilation as a result of exercise training in patients with obstructive lung disease. Am Rev Respir Dis 1991; 143: 9-18.

6 O’Donnell DE, Revill SM, Webb KA. Dynamic hyperinflation and exercise intolerance in chronic obstructive pulmonary disease. Am J Respir Crit Care Med 2001; 164: 770-777.

7 O'Donnell DE, Bain DJ, Webb KA. Factors contributing to relief of exertional breathlessness during hyperoxia in chronic airflow limitation. Am J Respir Crit Care Med 1997; 155: 530-535.

8 O'Donnell DE, D'Arsigny C, Webb KA. Effects of hyperoxia on ventilatory limitation during exercise in advanced chronic obstructive pulmonary disease. Am J Respir Crit Care Med 2001; 163: 892-898.

9 Ekstrom M, Ahmadi Z, Bornefalk-Hermansson A, et al. Oxygen for breathlessness in patients with chronic obstructive pulmonary disease who do not qualify for home oxygen therapy. Cochrane Database Syst Rev 2016; 11: CD006429.

10 Bradley JM, O'Neill B. Short-term ambulatory oxygen for chronic obstructive pulmonary disease. Cochrane Database Syst Rev 2005; 4: CD004356.

11 Emtner M, Porszasz J, Burns M, et al. Benefits of supplemental oxygen in exercise training in nonhypoxemic chronic obstructive pulmonary disease patients. Am J Respir Crit Care Med 2003; 168: 1034-1042.

12 Neunhauserer D, Steidle-Kloc E, Weiss G, et al. Supplemental oxygen during high-intensity exercise training in nonhypoxemic chronic obstructive pulmonary disease. Am J Med 2016; 129: 1185-1193.

13 Jenkins S, Hill K, Cecins NM. State of the art: how to set up a pulmonary rehabilitation program. Respirology 2010; 15: 1157-1173.

14 Rooyackers JM, Dekhuijzen PN, Van Herwaarden CL, et al. Training with supplemental oxygen in patients with COPD and hypoxaemia at peak exercise. Eur Respir J 1997; 10: 1278-1284.

15 Garrod R, Paul EA, Wedzicha JA. Supplemental oxygen during pulmonary rehabilitation in patients with COPD with exercise hypoxaemia. Thorax 2000; 55: 539-543.

16 Wadell K, Henriksson-Larsen K, Lundgren R. Physical training with and without oxygen in patients with chronic obstructive pulmonary disease and exercise-induced hypoxaemia. J Rehabil Med 2001; 33: 200-205.

17 Spielmanns M, Fuchs-Bergsma C, Winkler A, et al. Effects of oxygen supply during training on subjects with COPD who are normoxemic at rest and during exercise: a blinded randomized controlled trial. Respir Care 2015; 60: 540-548.

18 Alison JA, McKeough ZJ, Jenkins SC, et al. A randomised controlled trial of supplemental oxygen versus medical air during exercise training in people with chronic obstructive pulmonary disease: supplemental oxygen in pulmonary rehabilitation trial (SuppORT). BMC Pulm Med 2016; 16: 25.

19 Miller MR, Hankinson J, Brusasco V, et al. Standardisation of spirometry. Eur Respir J 2005; 26: 319-338.

20 Holland AE, Spruit MA, Troosters T, et al. An official European Respiratory Society/American Thoracic Society technical standard: field walking tests in chronic respiratory disease. Eur Respir J 2014; 44: 1428-1446.

21 Hill K, Jenkins S, Cecins N, et al. Estimating maximum work rate during incremental cycle ergometry testing from six-minute walk distance in patients with chronic obstructive pulmonary disease. Arch Phys Med Rehabil 2008; 89: 1782-1787.

22 Borg GAV. Psychophysical bases of perceived exertion. Med Sci Sports Exerc 1982; 14: 377-381.

23 American Thoracic Society, American College of Chest Physicians. ATS/ACCP Statement on cardiopulmonary exercise testing. Am J Respir Crit Care Med 2003; 167: 211-277.

24 Revill S, Morgan M, Singh S, et al. The endurance shuttle walk: a new field test for the assessment of endurance capacity in chronic obstructive pulmonary disease. Thorax 1999; 54: 213-222.

25 Guyatt GH, Berman LB, Townsend M, et al. A measure of quality of life for clinical trials in chronic lung disease. Thorax 1987; 42: 773-778.

26 Singh S, Morgan M, Scott S, et al. Development of a shuttle walking test of disability in patients with chronic airways obstruction. Thorax 1992; 47: 1019-1024.

27 Yorke J, Moosavi SH, Shuldham C, et al. Quantification of dyspnoea using descriptors: development and initial testing of the Dyspnoea-12. Thorax 2010; 65: 21-26.

$28 \mathrm{Ng} \mathrm{C}$, Watts S, McKeough Z, et al. Minimal detectable difference for the endurance shuttle walk test following ground walking training in people with COPD. Respirology 2013; 18: Suppl. 1, 56.

29 Leung RW, Alison JA, McKeough ZJ, et al. Ground walk training improves functional exercise capacity more than cycle training in people with chronic obstructive pulmonary disease (COPD): a randomised trial. J Physiother 2010; 56: 105-112.

30 Schunemann HJ, Puhan M, Goldstein R, et al. Measurement properties and interpretability of the chronic respiratory disease questionnaire (CRQ). COPD 2005; 2: 81-89.

31 Ries A, Kaplan R, Myers R, et al. Maintenance after pulmonary rehabilitation in chronic lung disease: a randomized trial. Am J Respir Crit Care Med 2003; 167: 880-888. 
32 Morris NR, Walsh J, Adams L, et al. Exercise training in COPD: what is it about intensity? Respirology 2016; 21: $1185-1192$.

33 American College of Sports Medicine. Guidelines for Exercise Testing and Prescription. Philadelphia, Wolters Kluwer Health, 2017.

34 Jaeschke R, Singer J, Guyatt GH. Measurement of health status: ascertaining the minimum clinically important difference. Control Clin Trials 1989; 10: 407-415.

35 Dyer F, Callaghan J, Cheema K, et al. Ambulatory oxygen improves the effectiveness of pulmonary rehabilitation in selected patients with chronic obstructive pulmonary disease. Chron Respir Dis 2012; 9: 83-91.

36 Bradley JM, O’Neill BM. Short-term ambulatory oxygen for chronic obstructive pulmonary disease. Cochrane Database Syst Rev 2009; 2: CD002769.

37 Gimeno-Santos E, Frei A, Steurer-Stey C, et al. Determinants and outcomes of physical activity in patients with COPD: a systematic review. Thorax 2014; 69: 731-739.

38 Spruit MA, Pitta F, Garvey C, et al. Differences in content and organisational aspects of pulmonary rehabilitation programmes. Eur Respir J 2014; 43: 1326-1337.

39 Jolly EC, Di Boscio V, Aguirre L, et al. Effects of supplemental oxygen during activity in patients with advanced COPD without severe resting hypoxemia. Chest 2001; 120: 437-443.

40 Heraud N, Prefaut C, Durand F, et al. Does correction of exercise-induced desaturation by $\mathrm{O}_{2}$ always improve exercise tolerance in COPD? A preliminary study. Respir Med 2008; 102: 1276-1286. 